\title{
PERANCANGAN E-COMMERCE PADA BINTANG FASHION MENGGUNAKAN PHP \& LARAVEL FRAMEWORK
}

\author{
Fahmi Dwi Ramdiansyah ${ }^{1)}$, Dian Anubhakti ${ }^{2)}$ \\ ${ }^{1}$ Sistem Informasi, Fakultas Teknologi Informasi, Universitas Budi Luhur \\ ${ }^{1,2} \mathrm{Jl}$. Raya Ciledug, Petukangan Utara, Kebayoran Lama, Jakarta Selatan 12260 \\ E-mail: ramdiansyah1302@gmail.com ${ }^{1)}$, dian.anubhakti@budiluhur.ac.id²)
}

\begin{abstract}
Abstrak
Bintang Fashion merupakan sebuah bisnis ritel pakaian dengan di produksi dan design home industry dengan brand milik sendiri. Bintang Fashion ini berlokasi di Jalan Kedung Waringin No 18A Bojong gede, Kab.Bogor. Masalah yang kerap dihadapi pada Bintang Fashion antara lain pengecekan stok produk masih menggunakan penghitungan manual, kebutuhan akan informasi produk sulit dicari, membuat pelayanan pada bintang fashion jadi lambat, stok lama yang dimiliki Bintang Fashion sulit terjual, sehingga pihak toko mengalami kesulitan dalam memasarkan stok lama, penjualan yang dilakukan masih penjualan konvesional yaitu menunggu pelanggan datang dan membeli barang. Dari masalah tersebut akan membuat hasil penjualan menurun. Dengan teknologi yang sekarang berkembang pesat, memungkinkan untuk mendukung bisnis menjadi lebih maju dan berkembang. Hal tersebut menjadi peluang untuk mengatasi masalah yang terjadi pada Bintang Fashion Dengan merancang sistem penjualan berbasis web e-commerce yang terkomputerisasi dengan memanfaatkan teknologi, yang diharapkan mampu memberikan dampak positif bagi Bintang Fashion. Sehingga kegiatan penjualan menjadi meningkat dan mampu bertahan dan bersaing dengan bisnis serupa yang ada saat ini. Penulis mengimplementasikan dengan menggunakan bahasa pemrograman PHP dan Framework Laravel, dan menggunakan database PostgreSQL. Penulis berharap dengan adanya rancangan sistem penjualan berbasis web ecommerce yang terkomputerisasi, dapat mempermudah Bintang Fashion dalam mengatasi masalahmasalah yang sering terjadi.
\end{abstract}

Kata kunci: Distro, E-Commerce, Bintang Fashion

\section{PENDAHULUAN}

Kehadiran E-Commerce atau biasa yang disebut dengan toko online yang menjadi suatu media transaksi bisnis ini tentunya menguntungkan banyak pihak, baik pihak produsen, pihak konsumen maupun pihak penjual. Dengan media transaksi baru ini tentunya memberikan keuntungan yang memudahkan proses transaksi dengan menggunakan internet, prosesnya dapat dilakukan dengan efisien dalam bentuk penghematan biaya, waktu dan juga tenaga.

E-commerce adalah transaksi pertukaran atau pertukaran informasi di dunia maya. [1] Munculnya e-commerce tidak terlepas dan perkembangan teknologi informasi yang begitu maju khususnya internet.

Sistem adalah suatu komponen kerja dari prosedur-prosedur yang berhubungan satu sama lain, dan berkumpul bersama-sama untuk melakukan suatu kegiatan atau menyelesaikan suatu sasaran yang tertentu.

Sistem dapat diartikan sebagai "suatu kumpulan dari komponen-komponen yang membentuk satu kesatuan”. [2]

Analisa sistem adalah penguraian sistem informasi yang utuh kedalam bagian komponen yang bertujuan untuk mengidentifikasi dan mengevaluasi permasalahan, kesempatan, dan hambatan yang terjadi dan menentukan kebutuhan sehingga dapat diusulkan perbaikannya.

Analisa sistem dapat diartikan sebagai "teknik pemecah masalah yang menguraikan bagian-bagian komponennya dengan mempelajari seberapa bagus komponen-komponen dengan mempelajari seberapa bagus komponen tersebut bekerja dan berinteraksi dalam mencapai tujuan mereka. [3]

Perancangan adalah proses merencanakan segala sesuatu terlebih dahulu. Perancangan adalah wujud visual yang dihasilkan dari bentuk-bentuk kreatif yang telah direncanakan. [4]

UML adalah suatu bahasa yang digunakan untuk menentukan, membangun, dan mendokumentasikan suatu sistem informasi.

UML adalah sebuah teknik pengembangan sistem yang menggunakaan bahasa grafis sebagai alat mendokumentasikan dan melakukan spesifikasi pada sistem. [5]

PHP (hypertext Preprocessor) adalah suatu bahasa pemograman yang digunakan untuk menerjemahkan baris kode program menjadi kode program menjadi kode mesin yang dapat diterjemahkan oleh sistem komputer yang berbasis server-side yang dapat ditambah kedalam HTML. [6]

Laravel adalah sebuah Framework PHP dirilis dibawah lisensi MIT dengan kode yang sudah 
disediakan oleh Github, sama seperti frameworkframework yang lain. Laravel dibangun dengan konsep MVC (Model-Controller-View), kemudian Laravel dlengkapi juga dengan command line tool yang bernama "Artisan” yang bisa digunakan untuk packaging bundle dan instalasi bundle melalui command prompt. [7]

\section{PENELITIAN SEBELUMNYA}

Naskah publikasi berjudul: Implementasi ECommerce Toko Prayoga Sport Berbasis Content Management System (CMS) Joomla Modules VirtualMart”. menjelaskan bahwa toko-toko konvensional belum mengenal pengembangan bisnis melalui internet. Prayoga Sport yang berdaerah di Cikupa, Kecamatan Tangerang adalah salah satu bisnis toko yang menjual berbagai macam sepatu sepatu yang mengandalkan menunggu pembeli untuk datang ke toko. Permasalahan yang terjadi pada, toko Prayoga Sport adalah meliputi kurang melakukan promosi sehingga toko prayoga sport kurang dikenal dan juga masih mengandalkan pembeli datang ke toko sehingga penjualannya tidak meningkat. Untuk itulah peneliti mengidentifikasi kebutuhan bisnis pada Toko Prayoga Sport dan mengimplementasikan sistem E-Commerce dengan menggunakan CMS Joomla modules VirtueMart yang sesuai untuk diterapkan.Tujuannya untuk melakukan pemasaran lewat online. Manfaat yang didapat dari implementasi sistem E-Commerce dengan menggunakan CMS Joomla modules VirtueMart bagi konsumen adalah konsumen kini hanya perlu melakukan transaksi lewat website saja tanpa perlu datang ke toko. Bagi penjual adalah mempermudah transaksi jual beli dan juga bisa untuk sebagai media promosi. [8]

Naskah publikasi berjudul: "perancangan sistem informasi penjualan berbasis e-commerce pada Toko Kun Jakarta”. Tujuan dari penelitian ini adalah memberi solusi atas masalah-masalah yang ada pada Toko Kun Jakrta dengan merancang dan mengimplementasikan sebuah sistem informasi penjualan berbasis e-commerce, ILKOM Jurnal Ilmiah Volume 10 Nomor 2 Agustus 2018 p-ISSN 2087-1716 dan e-ISSN 2548-7779, kesimpulan dari penelitian ini adalah media website e-commerce mempermudah transaksi jual atau beli secara online, dan juga bisa juga sebagai tempat media promosi, serta dapat memudahkan dalam pengolahan data dan pembuatan laporan yang sekarang sudah terkomputerisasi. Bagi konsumen yaitu konsumen dapat memperoleh informasi produk secara cepat dan akurat, dan dapat melakukan transaksi melalui website secara online tanpa harus datang ke toko. [9]

\section{METODE PENELITIAN}

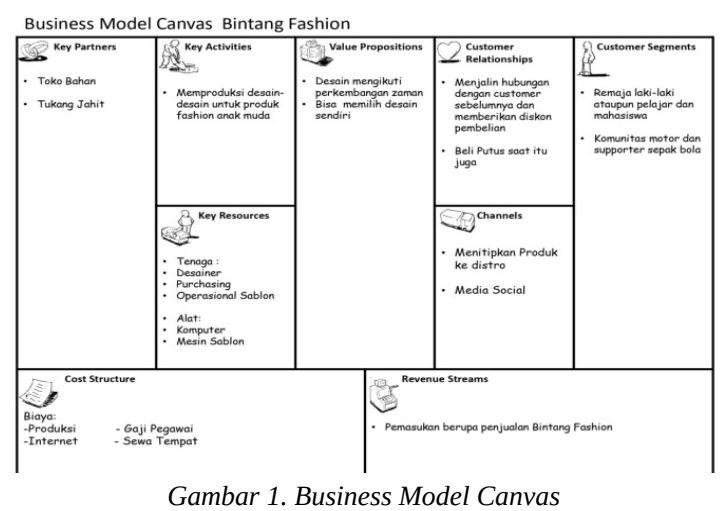

Business Model Canvas (BMC) adalah suatu cara yang tepat untuk mendeskripsikan model bisnis juga menggambarkan dasar pemikiran tentang bagaimana organisasi menciptakan, memberikan, dan menangkap sebuah nilai. Business Model Canvas adalah alat untuk membantu para pemodal bisnis untuk melihat lebih lanjut tentang usaha yang sedang dijalani atau akan dijalani. Mengganti rancangan bisnis yang kompleks menjadi lebih sederhana yang ditampilkan pada satu lembar kanvas berisi rencana bisnis dengan sembilan point penting yang terintegrasi dengan baik didalamnya mencakup analisis strategi secara internal maupun eksternal perusahaan. [10]

a. Customer Segment

Segmentasi Pelanggan atau target pemasaran menguraikan kelompok orang atau organisasi yang ingin digapai.

b. Value Proposition

Value Proposition menguraikan antara produk dan layanan yang menciptakan nilai untuk pelanggan yang spesifik.

c. Channel

Saluran (Channel) menguraikan bagaimana sebuah bisnis melakukan komunikasi dengan Pelanggannya dan membuat mereka untuk memberikan Value Proposition.

d. Customer Relationship

Hubungan Pelanggan mendeskripsikan hubungan yang dibangun pebisnis dengan customer atau mitra.

e. Revenue Stream

Revenue Stream menggambarkan uang yang dihasilkan perusahaan dari masing-masing Segmen Pelanggan.

f. Key Resources

Key Resources menguraikan asset-asset yang diperlukan untuk sebuah bisnis agar dapat bekerja maksimal.

g. Key Activities 
Key Activities menguraikan point-point penting yang akan dilakukan pebisnis agar bisnisnya dapat berjalan.

h. Key Partnership

kemitraan utama menggambarkan pemasok bisnis dan mitra bisnis yang membuat bisnis perusahaan dapat bekerja.

i. Cost Structure

Cost Structure menguraikan pengeluaran apa saja yang dikeluarkan untuk mengeoperasikan bisnis.

\section{HASIL DAN PEMBAHASAN}

4.1. Proses Bisnis Usulan

a. Pemesanan Produk

Proses alur pemesanan produk dilakukan dengan pelanggan masuk ke sistem website kemudian memilih produk yang ingin dibeli lalu klik tombol add cart atau keranjang untuk menambahkan produk kedalam cart selesai memilih produk masuk kedalaman cart kemudian pelanggan input jumlah produk yang ingin dipesan setelah itu pelanggan klik tombol buat pesanan kemudian sistem akan melakukan pengecekan apakah pelanggan sudah melakukan login atau belum jika pelanggan sudah melakukan login maka pesanan akan dibuat oleh sistem jika pelanggan belum login pelanggan masuk ke halaman login kemudian pesanan akan dibuat oleh sistem kemudian sistem akan mengirimkan bukti pesanan dan kode pesanan.

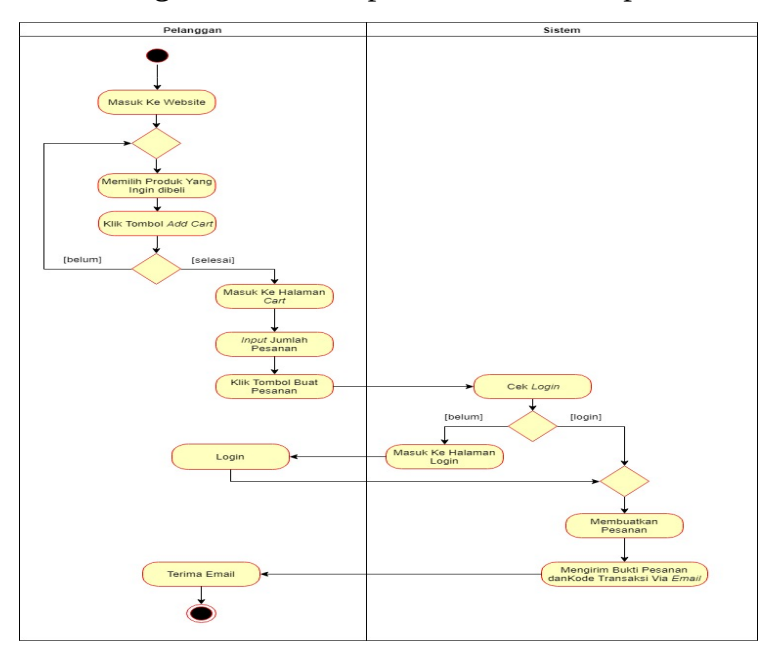

Gambar 2. Activity Diagram Pemesanan Produk

Pada gambar 2 menjelaskan tentang bagaimana proses pemesanan produk pada sistem usulan di Bintang Fashion.

b. Konfirmasi Pembayaran

Setelah pelanggan selesai pemesanan produk, pelanggan melakukan melakukan pembayaran sesuai dengan bukti pemesanan dan pembayaran dilakukan dengan cara transfer. setelah pelanggan melakukan pembayaran pelanggan harus masuk ke website dan login kemudian pelanggan masuk ke halaman konfirmasi pembayaran dan menginput data pembayaran dan upload bukti pembayaran yang telah dilakukan setelah itu pelanggan klik tombol submit jika telah selesai menginput data. Kemudian admin akan mengecek pembayaran apabila pembayaran sesuai maka admin akan memverifikasi dan mengubah status pembayaran kemudian sistem akan mengirimkan invoice via email ke pelanggan.

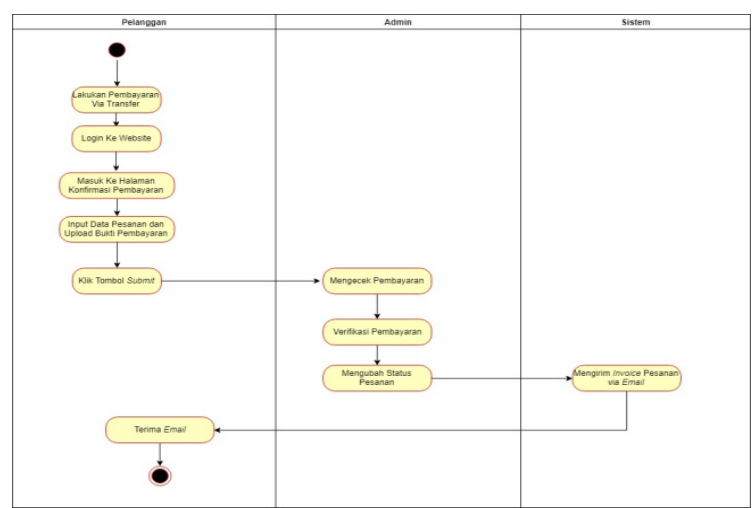

Gambar 3. Activity Diagram Konfirmasi Pembayaran

Pada gambar 3 menjelaskan tentang bagaimana proses Konfirmasi Pembayaran pada sistem usulan di Bintang Fashion.

\subsection{Use Case Diagram}

a. Use Case Diagram Master

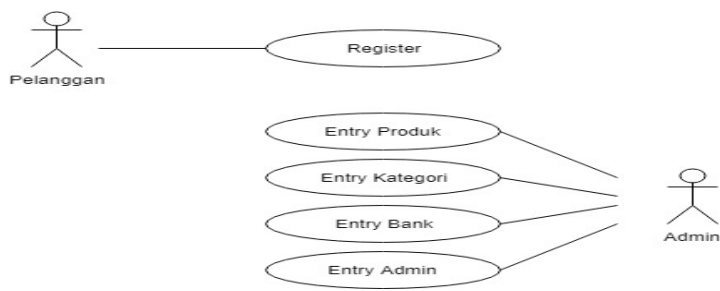

Gambar 4. Use Case Diagram Master

Pada gambar 4 menjelaskan apa saja yang ada di pada master.

b. Use Case Diagram Transaksi Pelanggan

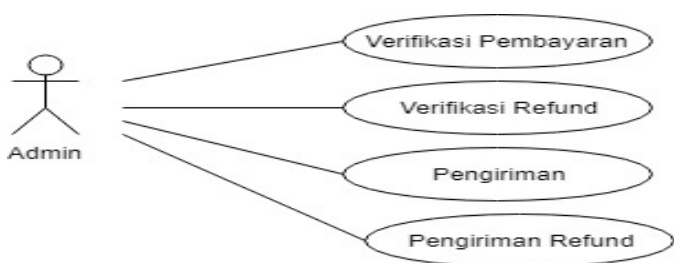

Gambar 5. Use Case Diagram Transaksi Pelanggan 
Pada gambar 5 menjelaskan apa saja yang ada di pada Transaksi Pelanggan.

c. Use Case Diagram Transaksi Admin

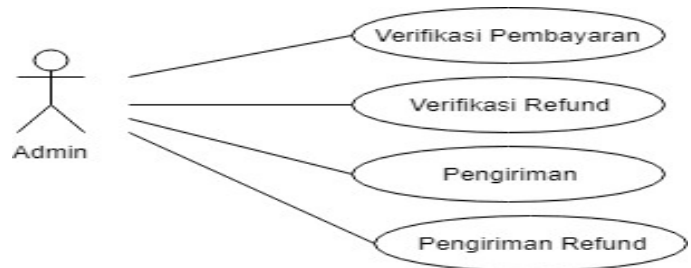

Gambar 6. Use Case Diagram Transaksi Admin

Pada gambar 6 menjelaskan apa saja yang ada di pada Transaksi Admin.

\section{d. Use Case Diagram Laporan}

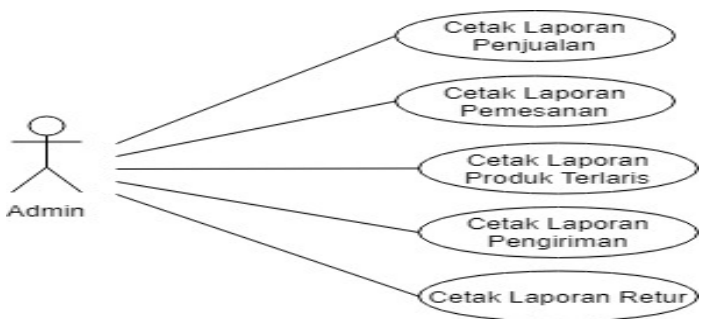

Gambar 7. Use Case Diagram Laporan

Pada gambar 7 menjelaskan apa saja yang ada di pada Laporan.

\subsection{Class Diagram}

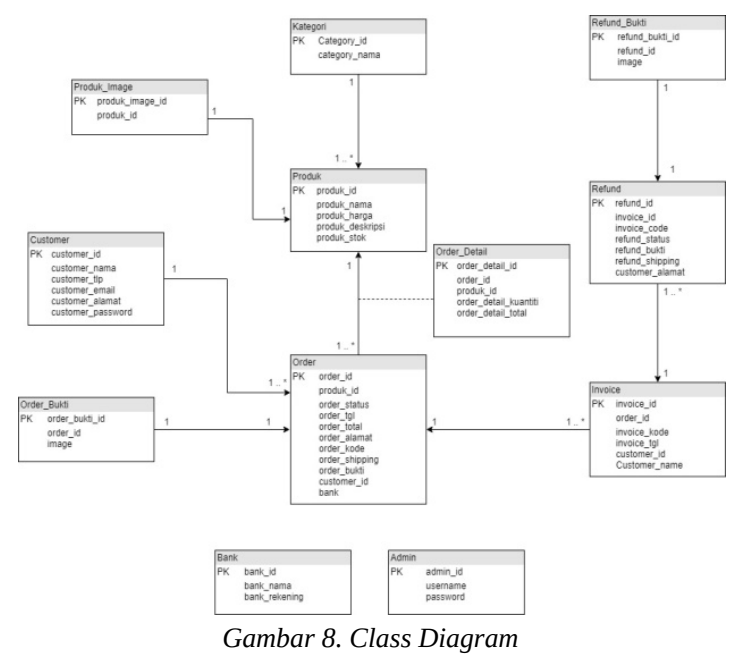

Pada gambar 8 menjelaskan apa saja class-class yang ada pada Website.

\subsection{Rancangan Layar}

a. Rancangan Layar Data Barang

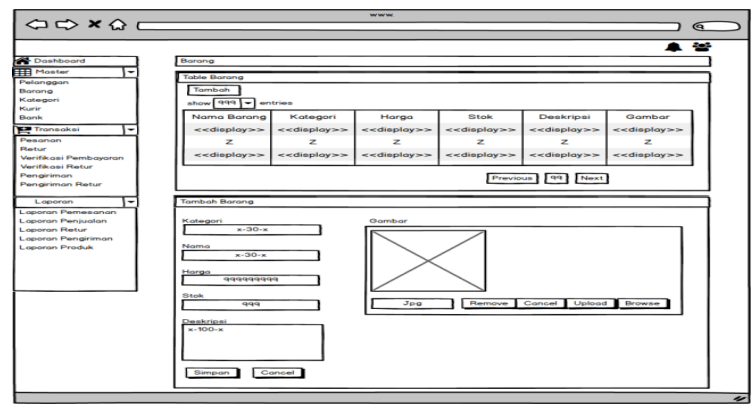

Gambar 9. Rancangan Layar Data Barang

Pada gambar 9 menjelaskan tentang data barang yang telah atau akan di entri oleh admin

b. Rancangan Layar Login Pelanggan

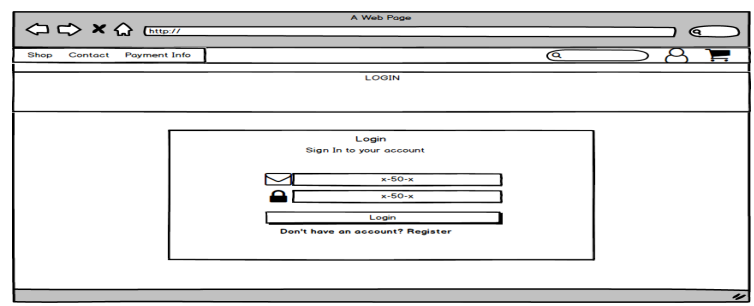

Gambar 10. Rancangan Layar Login Pelanggan

Pada gambar 10 menjelaskan tentang rancangan layar login pelanggan.

c. Rancangan Layar Cart

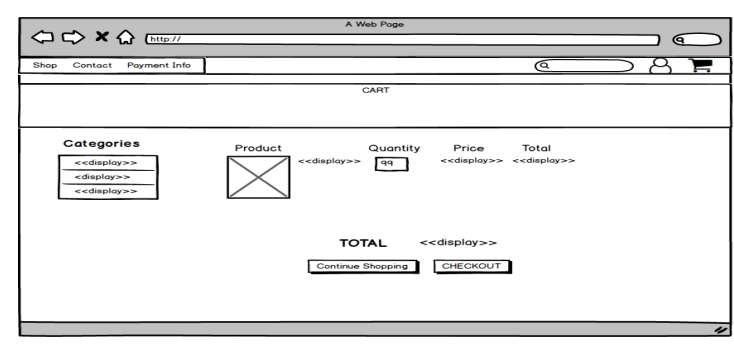

Gambar 11. Rancangan Layar Cart

Pada gambar 11 menjelaskan tentang rancangan layar cart.

\subsection{Sequence Diagram}

a. Sequence Diagram Barang 


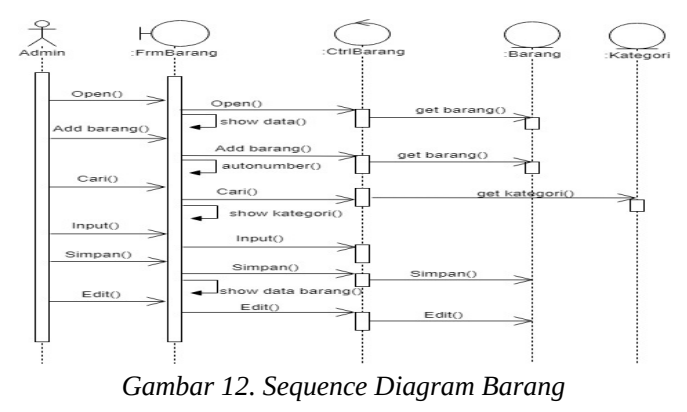

Pada gambar 12 menjelaskan alur bagaimana cara menyimpan data barang diwebsite

\section{b. Sequence Diagram Admin}

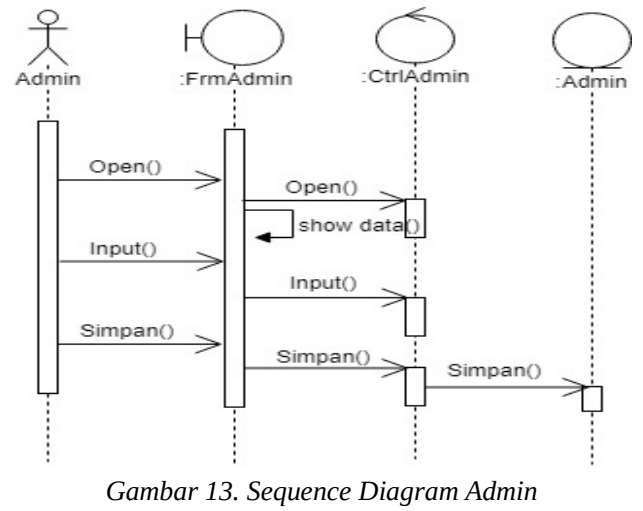

Pada gambar 13 menjelaskan alur bagaimana cara menyimpan data admin diwebsite

\section{c. Sequence Diagram Pemesanan}

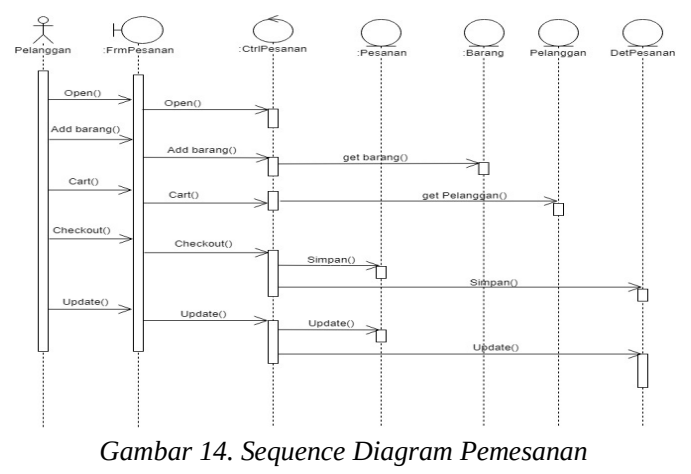

Pada gambar 14 menjelaskan tentang alur sequence diagram pada tampilan pemesanan pelanggan.

\subsection{Strategi SEO dan Marketing}

a. Metode SEO On-Page

Metode SEO On-Page merupakan pengaturan SEO yang dilakukan dari dalam website itu sendiri.
Metode SEO Off-Page merupakan pengaturan SEO yang dilakukan dari luar website itu sendiri

\section{KESIMPULAN}

Berdasarkan hasil analisa yang telah dilakukan pada Bintang Fashion, maka dapat disimpulkan:

1) Dengan adanya website e-commerce ini memudahkan staff toko melakukan pengecekan stok produk.

2) Dengan adanya website e-commerce ini memudahkan pelanggan untuk melakukan pemesanan tanpa harus datang ke toko.

3) Dengan adanya website e-commerce ini Mempermudah pemilik toko untuk memasarakan stok produk lama yang menumpuk.

4) Dengan adanya website e-commerce ini mempermudah staff toko untuk mengetahui informasi produk yang di cari.

\section{DAFTAR PUSTAKA}

[1] Renung, Rintho Rante . E-Commerce, Menciptakan Daya Saing Melalui Teknologi Informasi. Yogyakarta: Deepublish. 2018

[2] Tyoso, Jaluanto Sunu Punjul. Deepublish, "Sistem Informasi Manajemen”. Yogyakarta: Deepublish. 2016

[3] Muslihudin, Muhamad. And Oktafianto. Analisis dan Perancangan Sistem Informasi Menggunakan Model Terstruktur dan UML. Yogyakarta: Andi. 2016

[4] Hidayat, Wahyu., Fauzi, Maaruf., Saeful, Bahari. () "Perancangan Media Video Desain Interior Sebagai Salah Satu Penunjang Promosi Dan Informasi Di PT. Wans Desain Group”. Jurnal CERITA Vol. 2 No. 1 Februari 2016" 2016

[5] Mulyani NS, Sri. Analisis dan perancangan sistem informasi manajemen keuangan daerah: notasi pemodelan unified model language (UML). Bandung: abdi sistematika. 2016

[6] Supono. And Putratama, Virdiandry. () Pemrograman Web dengan Menggunakan PHP dan Framework Codeigniter. Supono. 2016

[7] Aminudin. Cara Efektif Belajar Framework LARAVEL. Yogyakarta: Lokomedia 2015

[8] Dedi. And Mustofa., Siti Maisaroh, Suhartono. Implementasi E-Commerce Toko Prayoga Sport Berbasis Content Management System (CMS) Joomla Modules Virtuemart. 2017, ISSN 2088-1762.

[9] Handayani, Sutri. Perancangan Sistem Informasi Penjualan Berbasis E-Commerce Studi Kasus Toko Kun Jakarta, 2018, ISSN 2087-1716 dan e-ISSN 2548-7779.

[10] Osterwalder, Alexander. And Pigneur. Business Model Gneration. Jakarta: PT Elex Media Komputindo. 2012

\section{b. Metode SEO Off-Page}

